\title{
Transferrin Receptors on the Human Placental Microvillous Membrane
}

\author{
T. T. Loh, D. A. Higuchi, F. M. van Bockxmeer, C. H. Smith, and \\ E. B. Brown, Division of Hematology-Oncology, Department of Medicine \\ and Departments of Pediatrics and Pathology, Washington University School \\ of Medicine, St. Louis, Missouri 63110
}

\begin{abstract}
A B S T RACT A preparation of microvillous membrane vesicles from human placental syncytiotrophoblast binds transferrin to specific transferrin receptors. Transferrin binding to placental receptors is rapid, saturable, reversible, and specific. Approximately 2.5 $\times 10^{13}$ receptors are present per milligram of membrane protein; the apparent association constant of transferrin for the placental receptor is $2.2 \times 10^{7}$ $\times \mathbf{M}^{-1}$. No evidence for removal of iron from transferrin bound to intact membrane receptors was observed in these studies. Nonionic detergent solubilization and partial purification of the microvillous membrane transferrin receptor were carried out with preservation of the functional properties of the receptor.
\end{abstract}

\section{INTRODUCTION}

During the course of gestation a large amount of iron is transferred against a concentration gradient rapidly and unidirectionally from mother to fetus across the placenta (1-9). Ferrokinetic studies in $\operatorname{man}(1,2)$ and in experimental animals with hemochorial placentas (3-8) show that the major placental transfer of iron occurs late in gestation. The exclusive source of this iron which is transferred to the fetus is the extremely stable transferrin-iron complex (the stability constant at physiologic $\mathrm{pH}$ and $\mathrm{PCO}_{2}$ is $\sim 10^{24} \mathrm{M}^{-1}$ [10]) in the maternal plasma. Maternal transferrin which binds to placental tissue does not cross the placenta to the fetal circulation (11). As gestation progresses, transferrin uptake by the placenta increases proportionately as the rate of iron delivery to the fetus increases (11). Uptake

Preliminary findings of this study were presented in part at the 17th International Congress of Hematology, Paris, France, July 1978.

Dr. Loh's present address is Department of Physiology, Medical Faculty, University of Hong Kong.

Received for publication 8 November 1978 and in revised form 21 January 1980. of both transferrin and iron is not affected by removal of the fetus, indicating that these placental functions are independent of fetal requirements (4). Consequently, it has been proposed that the maternal transferrin-iron complex is taken up by receptors on the placental surface followed by removal of its iron. This iron is transported through the placenta and becomes associated with fetal transferrin in the fetal circulation (11). The iron-depleted maternal transferrin is then returned to the maternal circulation enabling it to participate in further cycles of plasma-to-placenta iron exchange.

Laurell and Morgan (12) postulated that the maternal transferrin-iron complex first attaches to specific receptors on the surface of the placenta before iron is removed from the transferrin, and van Bockxmeer et al. (13) identified a transferrin-binding protein in detergent extracts of rabbit placentas. Receptors have been inferred from the discrete patches of transferrin observed on the surface of human placenta microvilli by electron microscopic immunocytochemical methods (14). By modifying the methods of N. C. Smith et al. (15) and C. H. Smith and co-workers $(16,17)$ we characterized a microvillous membrane vesicle preparation from human syncytiotrophoblast and showed that the vesicles were similar in shape, size, and microfilamentous content with those of intact placental microvilli. These vesicles were enriched in enzymes characteristic of plasma membranes and were relatively devoid of enzymes characteristic of other organelles. Electron micrographs of membrane vesicles prepared for localization of transferrin by the peroxidase-antiperoxidase unlabeled antibody method showed that transferrin was specifically bound to the outer surface of the vesicles (16). This isolated microvillous membrane preparation thus seemed ideal to examine transferrinbinding to specific receptors on the placental syncytiotrophoblast. In this paper we report on the interaction between human transferrin and specific receptors on the microvillous membrane of human placenta and the partial characterization of these transferrin receptors. 


\section{METHODS}

Microvillous membrane preparation. Placentas were obtained immediately after delivery from women who had vaginal deliveries or elective cesarean sections at term. Microvillous membrane vesicles were prepared from these placentas by the method of Smith et al. (16). The protein concentration of the final microvillous membrane suspension ranged from 2.5 to $6.0 \mathrm{mg} / \mathrm{ml}$ of suspension as measured by the Lowry et al. method (18). In addition, $200 \mathrm{U}$ of Trasylol (FBA Pharmaceuticals, Inc., New York) were added to the vesicles to minimize possible proteolytic activity. Microvillous membrane suspensions were studied within $4 \mathrm{~h}$ of preparation.

Labeling of proteins. Human apotransferrin (Sigma Chemical Co., St. Louis, Mo.) was saturated with iron according to the method of Harris and Aisen (19) and further purified by gel filtration on a Sephacryl S-200 column $(2.5 \times 75 \mathrm{~cm})$ (Pharmacia Fine Chemicals, Div. of Pharmacia, Inc., Piscataway, N. J.) equilibrated with phosphate-buffered saline, $\mathrm{pH}$ 7.4 , and ion-exchange chromatography using DEAE-Sephacel (Pharmacia Fine Chemicals). The purity of the final product was $>98 \%$ as determined by electrophoresis on $10 \%$ polyacrylamide gels at $\mathrm{pH}$ 8.3. Proteins were labeled with carrier-free [ $\left.{ }^{125} \mathrm{I}\right]-$ or $\left[{ }^{131} \mathrm{I}\right]$ sodium iodide (New England Nuclear, Boston, Mass.) using the iodine monochloride method of McFarlane (20) to give an average maximum of one iodine atom per protein molecule. Apotransferrin was prepared as described by Harris et al. (21) and labeled with carrier and radioactive iron ${ }^{59} \mathrm{FeCl}_{3}$ (New England Nuclear) in the form of its complex with nitrilotriacetic acid (Eastman Kodak, Rochester, N. Y.) according to the method of Harris and Aisen (19) in amounts equivalent to $95 \%$ of its calculated iron binding capacity.

Binding assays. Aliquots $(100 \mu \mathrm{l})$ of the microvillous membrane suspension were diluted to a final volume of $1 \mathrm{ml}$ with Hepes-saline solution, $\mathrm{pH} 7.4$, containing radioactively labeled transferrin at $4^{\circ} \mathrm{C}$. The reaction mixture was made up in polycarbonate centrifugation tubes $(16 \times 85 \mathrm{~mm})$, which had previously been soaked in $5 \mathrm{mg} / \mathrm{ml}$ bovine serum albumin for at least $1 \mathrm{~h}$. Failure to precoat the tubes with albumin resulted in significant adsorption of labeled transferrin to the tubes confirming the findings of Phillips (22). All incubations were performed in a Dubnoff shaking water bath at $37^{\circ} \mathrm{C}$. At predetermined time intervals, samples were removed from the incubator, placed on ice, and the reaction terminated by the addition of $6 \mathrm{ml}$ ice-cold, enriched Hepes-buffered saline $(0.2 \%$ bovine serum albumin, $0.1 \%$ glucose in Hepessaline, $\mathrm{pH} 7.4$ ). The tubes were centrifuged for $15 \mathrm{~min}$ at $81,000 \mathrm{~g}$ in either a Spinco L or a Beckman L5-65 ultracentrifuge (Beckman Instruments, Inc., Spinco Div., Palo Alto, Calif.). The resultant membrane pellets were washed by resuspension in $6 \mathrm{ml}$ of the ice-cold, enriched Hepes-saline solution followed by centrifugation for $15 \mathrm{~min}$ at $81,000 \mathrm{~g}$. The final membrane pellets were transferred by resuspension in $1 \mathrm{ml}$ ice-cold enriched Hepes-saline to counting vials for measurement of radioactivity in a Beckman gamma 300 spectrometer (Beckman Instruments, Inc.).

Solubilization and analysis of microvillous membranes. Microvillous membrane suspensions were incubated with ${ }^{125}$ I-labeled transferrin as described above and extracted with nonionic detergent (Teric 12A9) according to the method of van Bockxmeer et al. (23). Extracts were centrifuged at $100,000 \mathrm{~g}$ for $1 \mathrm{~h}$ and the supernates were further studied by gel filtration, sucrose gradient ultracentrifugation, and sodium dodecyl sulfate polyacrylamide gel electrophoresis (SDS-PAGE). ${ }^{1}$

${ }^{1}$ Abbreviation used in this paper: SDS-PAGE, sodium dodecyl sulfate polyacrylamide gel electrophoresis.
For gel filtration studies columns $(1.5 \times 60 \mathrm{~cm})$ containing Ultrogel ACA34 (LKB, Stockholm, Sweden) were equilibrated with $0.1 \%$ Teric $12 \mathrm{~A} 9$ in $10 \mathrm{mM}$ Hepes-saline buffer, pH 7.4. Aliquots $(500 \mu \mathrm{l})$ of membrane extracts were applied and eluted with the equilibration buffer. Constant volume fractions (by weight) were collected for total protein and radioactivity measurement. Columns were calibrated under identical elution conditions with proteins of known molecular weight and Stokes radii (Pharmacia Fine Chemicals, high and low molecular weight calibration kits). These two parameters for transferrin and its placental receptor complex were estimated from calibration plots of $K_{\mathrm{Av}}$ vs. $\log$ molecular weight and $\sqrt{-\log \left(K_{A v}\right)}$ vs. Stokes radius.

Aliquots $(500 \mu \mathrm{l})$ obtained from either membrane extracts or gel filtration peaks were applied to linear sucrose density gradients (7-21\% [wt/vol]) containing 15 mosmol sodium phosphate buffer, $\mathrm{pH} 7.4$, and $1 \%$ Teric $12 \mathrm{~A} 9$, dispensed as a total volume of $5 \mathrm{ml}$ in cellulose nitrate centrifugation tubes. After centrifugation in a Beckman SW50.1 rotor (Beckman Instruments, Inc.) at $81,000 \mathrm{~g}$ for $17 \mathrm{~h}$ at $6^{\circ} \mathrm{C}, 200-\mu \mathrm{l}$ fractions were collected through the bottom of the centrifugation tubes. Samples of the microvillous membrane extracts, or of the various fractions from gel filtration and sucrose density centrifugation experiments, were analyzed by SDS-PAGE performed according to the method of Laemmli (24). Protein standards (myosin [200,000], $\beta$-galactosidase [116,500], phosphorylase $B[94,000]$, bovine serum albumin $[68,000]$, and ovalbumin $[43,000]$ ) for molecular weight by SDS-PAGE were purchased from Bio-Rad Laboratories, Richmond, Calif. (high and low molecular weight standards). For polyacrylamide gel electrophoresis in the presence of nonionic detergent, a modification of the Davis (25) method was used.

\section{RESULTS}

Effect of time on transferrin and iron uptake. Samples of microvillous membrane suspensions were incubated for various time intervals at $37^{\circ} \mathrm{C}$ with ${ }^{59} \mathrm{Fe}$ and ${ }^{125} \mathrm{I}$-labeled transferrin. The uptake of ${ }^{125} \mathrm{I}$-transferrin by the microvillous membrane preparation increased rapidly with the time of incubation and with the transferrin concentration in the incubation medium. Half-maximal binding was observed at $<5 \mathrm{~min}$ (Fig. 1A). At a fixed concentration of labeled transferrin in the incubation medium the timed uptake of the protein exhibited three distinct phases, viz., an "initial-binding" phase at zero time, a "progressive-binding" or "displacement" phase during the first $20 \mathrm{~min}$ of incubation, and a final "plateau" phase reached at $\sim 20 \mathrm{~min}$. This plateau was maintained for the remainder of the incubation period, which indicates that a steady-state value in transferrin binding had been reached by $\sim 20$ min and that the ability of the microvillous membrane preparation to bind transferrin was not diminished with continued incubation under these conditions. Similar results were observed with each series of incubations performed at fixed concentrations of transferrin over a wide range ( 1 to $100 \mu \mathrm{g} / \mathrm{ml}$ ) in the incubation medium. The results (Fig. 1A) also indicate that the placental membrane transferrin uptake increased in a nonlinear fashion with increasing concentrations of transferrin in the incubation medium. 

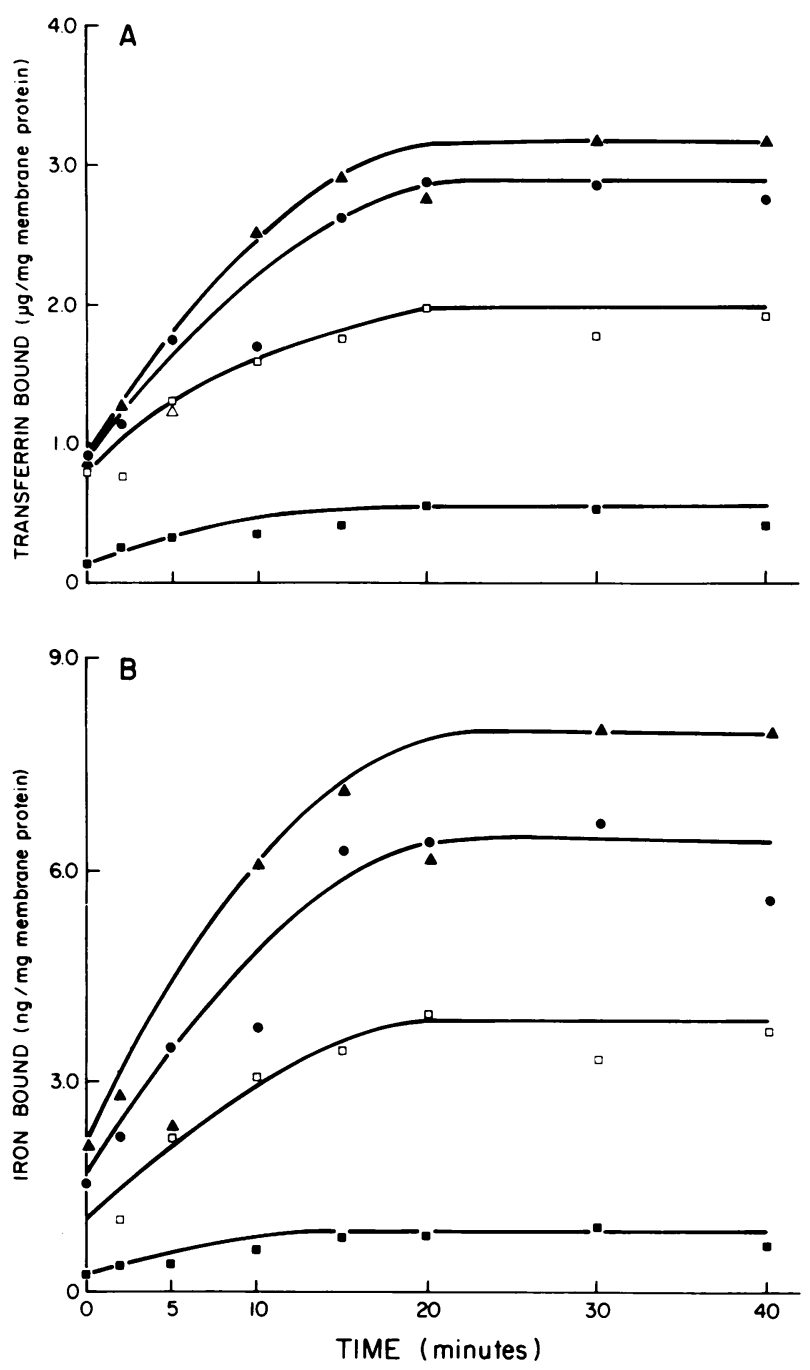

FIGURE 1 Effect of transferrin concentration and incubation time on transferrin and iron uptake. Suspensions containing $564 \mu \mathrm{g}$ placental microvillous membrane protein were incubated at $37^{\circ} \mathrm{C}$ (Methods) with ${ }^{125} \mathrm{I}$ - and ${ }^{59} \mathrm{Fe}$-labeled transferrin at concentrations of: $\square, 1 \mu \mathrm{g} / \mathrm{ml} ; \square, 8 \mu \mathrm{g} / \mathrm{ml} ; \bullet, 50$ $\mu \mathrm{g} / \mathrm{ml}$; and $\Delta, 100 \mu \mathrm{g} / \mathrm{ml}$. (sp act, ${ }^{125} \mathrm{I}$-transferrin, $3.81 \times 10^{3}$ $\left.\mathrm{cpm} / \mu \mathrm{g} ;{ }^{59} \mathrm{Fe}, 5.08 \times 10^{3} \mathrm{cpm} / \mu \mathrm{g}\right)$. The reaction mixtures were incubated for various time intervals from 2 to $40 \mathrm{~min}$; binding was terminated by quenching with cold Hepes-saline and radioactivity was measured (Methods). ${ }^{125}$ I-transferrin uptake is shown in panel $\mathrm{A}$ and ${ }^{59} \mathrm{Fe}$ uptake in panel $\mathrm{B}$.

During these studies the fate of the ${ }^{59} \mathrm{Fe}$ label presented as the specifically bound diferric complex with transferrin was also examined. The results (Fig. 1B) indicate that the binding of iron by the microvillous membrane preparations closely mirrored the uptake of transferrin as shown in Fig. 1A. This parallel uptake suggests that the iron bound to the membrane suspensions was bound as the transferrin-iron complex. There was no significant accumulation of iron relative to transferrin by the membrane preparations with either increased incubation intervals or with increased transferrin concentrations in the incubation media (Fig. 1B). Comparison of the curves shown in Fig. 1A and $B$ indicates that at each time interval the molar ratio of bound iron to bound transferrin is close to a value of two for all the curves.

Transferrin binding to microvillous membrane preparations. Steady-state binding of ${ }^{59} \mathrm{Fe}-$ and ${ }^{125} \mathrm{I}$ labeled transferrin to aliquots of microvillous membrane suspensions was investigated at transferrin concentrations in the range of 1 to $800 \mu \mathrm{g} / \mathrm{ml}$. To insure maximal binding, incubation times of 30 and 40 min were chosen for duplicate reaction mixtures. Control timed incubations were performed at fixed transferrin concentrations to verify that steady-state values were achieved. The results shown in Fig. 2 indicate that saturation of microvillous membrane transferrin binding sites occurred with increasing transferrin concentration. The total binding curves shown in this figure were not corrected for nonspecific binding. Estimates of nonspecific binding were obtained by two methods. The first method (26) involved linear regression analysis of the plateau portion of the binding curve obtained at transferrin concentrations between 120 and $800 \mu \mathrm{g} / \mathrm{ml}$. The resultant fit of the data was excellent and indicated that the maximal level of nonspecific binding at the highest transferrin concentration used $(800 \mu \mathrm{g} / \mathrm{ml})$ was only $11 \%$ of total binding. This low level of nonspecific binding was verified by separate experiments in which binding of labeled transferrin was measured in the presence of a 20 -fold excess of unlabeled transferrin. Four microvillous membrane preparations isolated from different placentas examined in this manner all showed very low levels of nonspecific binding. Over a transferrin concentration range of 1 to $60 \mu \mathrm{g} / \mathrm{ml}$, nonspecific binding was found to be insignificant $(<3 \%$ of total binding).

The binding data from Fig. 2 were analyzed by a double reciprocal plot method as shown in Fig. 3. The maximum number of transferrin binding sites was calculated from the intercept of the regression line on the ordinate. This value represents the maximum value of transferrin bound at saturating transferrin concentrations and may be equated with the number of binding sites present if it is assumed that each binding site binds only one transferrin molecule. The mean number of binding sites determined from analysis of seven experiments on four placentas was $2.5 \times 10^{13} / \mathrm{mg}$ microvillous membrane protein (range, $1.1 \times 10^{13}$ to $\left.4.2 \times 10^{13}\right)$. The apparent association constant of transferrin for the microvillous binding site was determined from the abscissal intercept of the regression line in Fig. 3. This value was $1.9 \times 10^{7} \mathrm{M}^{-1}$. The mean value in seven experiments was $2.2 \times 10^{7} \mathrm{M}^{-1}$ (range, $1.7 \times 10^{7} \mathrm{M}^{-1}$ to $\left.3.1 \times 10^{7} \mathrm{M}^{-1}\right)$. The results presented in Figs. 2 and 3 indicate the presence of a high affinity, 


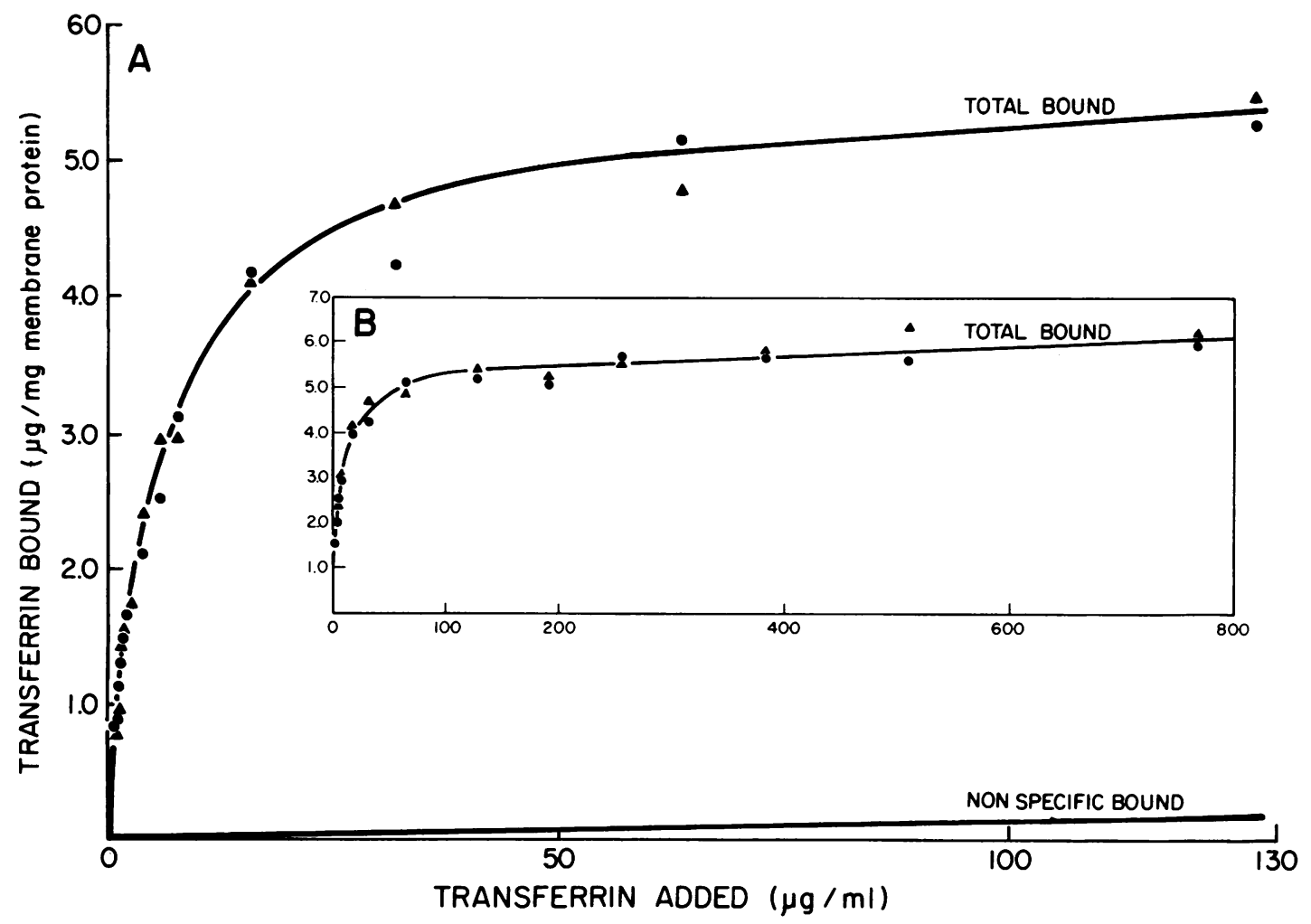

FIGURE 2 Steady-state binding of ${ }^{125}$ I-transferrin. Reaction mixtures containing $270 \mu$ g placental microvillous membrane protein and varying amounts of ${ }^{125}$ I-labeled transferrin $\left(\mathrm{sp}\right.$ act, $3.4 \times 10^{3}$ $\mathrm{cpm} / \mu \mathrm{g}$ protein) were incubated as described in the text. Bound ${ }^{125}$ I-labeled transferrin was measured (Methods) after $30 \mathrm{~min}(\Theta)$ and $40 \mathrm{~min}(\boldsymbol{\Delta})$ of incubation. In a parallel incubation it was determined that steady-state binding of transferrin had occurred by these incubation time intervals (cf. Fig. 1). Nonspecific ${ }^{125}$ I-labeled transferrin binding was estimated from uptake values in the concentration range from 130 to $800 \mu \mathrm{g} / \mathrm{ml}$ (inset B).

saturable, homogeneous, and noninteracting class of transferrin binding sites on the microvillous membrane preparation. The results also indicate the virtual absence of nonspecific (low affinity and "unsaturable") transferrin binding sites.

Reversibility of transferrin binding to the microvillous membrane preparation was also investigated. Aliquots of the membrane preparation were incubated as previously described (Methods) with $32 \mu \mathrm{g}$ of ${ }^{59} \mathrm{Fe}$ and ${ }^{125}$ I-labeled transferrin per milliliter incubation solution. This value was chosen in order to minimize nonspecific transferrin binding. When steady-state values of transferrin binding had occurred, selected incubation mixtures were removed and centrifuged for $15 \mathrm{~min}$ at $81,000 \mathrm{~g}$. After removal of the supernates, the membrane pellets were gently resuspended to their original volume in Hepes-buffered saline solutions containing a 50-fold or 100-fold excess of unlabeled transferrin. The samples were reincubated at $37^{\circ} \mathrm{C}$ and labeled transferrin binding was measured at the times indicated in Fig. 4. The results (Fig. 4) indicate that the addition of a large excess of unlabeled transferrin caused a rapid dissociation of labeled transferrin from the membrane preparation. Only $3-4 \%$ of the initial amount of labeled transferrin remained after $30 \mathrm{~min}$ of reincubation. The amount of iron bound to the membrane preparation after reincubation was also measured (not shown). The results confirmed that the iron originally bound to the membrane preparation was also removed during reincubation at a rate parallel to that of the transferrin.

Specificity of binding. Microvillous membrane preparations were incubated for $30 \mathrm{~min}$ at $37^{\circ} \mathrm{C}$ with increasing ${ }^{59} \mathrm{Fe}$ - and ${ }^{125}$ I-labeled transferrin concentrations in the incubation medium in the presence and absence of an equal concentration of ${ }^{131}$ I-labeled human serum albumin. Parallel incubations were performed in which a 20 -fold excess of unlabeled transferrin was added with the labeled transferrin. Throughout the range of transferrin concentration ( 1 to $130 \mu \mathrm{g}$ / $\mathrm{ml}$ ) studied (Fig. 5), low levels of nonspecific binding occurred as represented by the amount of labeled transferrin bound in the presence of excess unlabeled transferrin; nonspecific binding was $<10 \%$ of total 


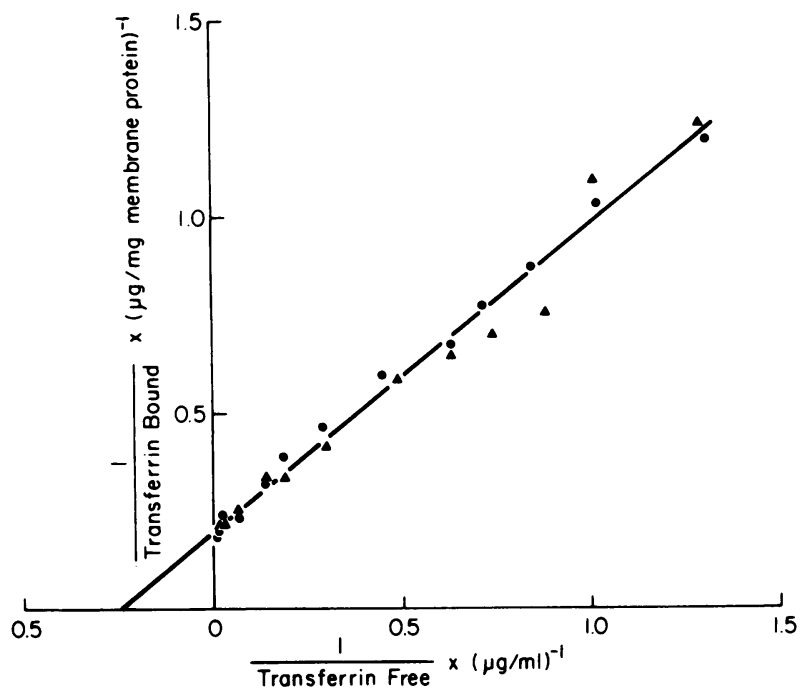

FIGURE 3 Double reciprocal plot of ${ }^{125}$ I-labeled transferrin bound to the placental microvillous membrane preparation vs. the free ${ }^{125} \mathrm{I}$-labeled transferrin concentration. These data were obtained from the experiments described in Fig. 2. The "line-of-best-fit" was obtained by linear regression analysis of the unweighted data.

binding at a transferrin concentration of $130 \mu \mathrm{g} / \mathrm{ml}$. The binding of labeled albumin to the microvillous membrane preparation was markedly different from that observed with transferrin. The amount of albumin

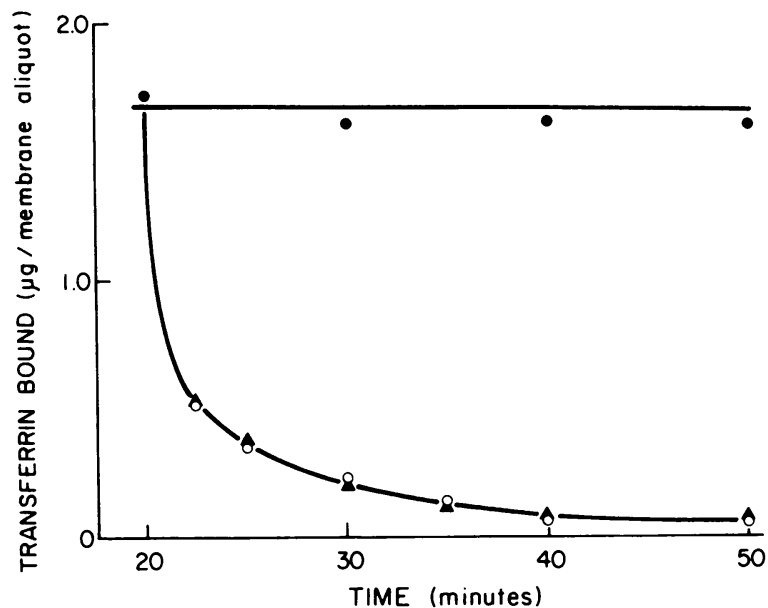

Figure 4 Dissociation of ${ }^{125} \mathrm{I}-{ }^{59} \mathrm{Fe}-$ labeled transferrin. Microvillous membrane suspensions were incubated with ${ }^{125} \mathrm{I}$ and ${ }^{59} \mathrm{Fe}$-labeled transferrin at a concentration of $32 \mu \mathrm{g} / \mathrm{ml}$ incubation medium at $37^{\circ} \mathrm{C}$ and the reaction terminated after 20 min (Methods). The membrane pellets obtained after centrifugation were incubated with buffer alone $(\Theta)$ or with a 50 -fold $(O)$ and 100-fold $(\Delta)$ excess of unlabeled transferrin as described in the text. Labeled transferrin remaining bound to the preparation at various reincubation times is shown. ${ }^{59} \mathrm{Fe}$ bound by the preparation (not shown) exactly mirrored transferrin binding. bound appeared to be a linear function of its concentration in the incubation medium, and is consistent with a nonspecific mode of uptake. The difference between transferrin and albumin binding was confirmed by the observations that transferrin binding was not significantly affected by the presence of albumin (Fig. 5). That is, albumin did not appear to compete with transferrin for its microvillous membrane binding site. Furthermore, the level of nonspecific albumin binding by the microvillous membrane preparation was about twice that of nonspecific transferrin binding over the concentration ranges studied.

Characteristics of the placental receptor-transferrin complex. Nonionic detergent extraction of microvillous membrane preparations previously incubated with labeled transferrin (Methods) resulted in the solubilization of $>85 \%$ of membrane-bound transferrin. Gel filtration of these extracts on Ultrogel AcA 34 (LKB Instruments, Rockville, Md.) (Fig. 6) gave elution profiles for labeled transferrin similar to those observed with transferrin receptors derived from reticulocytes $(27,28)$. About $40 \%$ of the labeled transferrin eluted in the same fraction as the marker transferrin (peak II). Up to $60 \%$ of the labeled transferrin in these membrane extracts was recovered as a high molecular weight moiety (peak I), which represented the placental receptor-transferrin complex. That this material was indeed the placental receptor-transferrin complex was verified by competition and displacement experiments (Fig. 6) where specificity and reversibility of transferrin binding was demonstrated. When human albumin was added in the ratio of $5 \mathrm{~mol}$ albumin/mol transferrin to a Teric extract of the microvillous membrane, it was incapable of displacing transferrin from the high molecular weight complex (Fig. 6). Likewise, human gamma globulin produced no displacement (data not shown). However, unlabeled transferrin at a molar ratio twice that of the ${ }^{125}$ I-labeled transferrin displaced $50 \%$ of the ${ }^{125}$ I-labeled transferrin from the high to low molecular weight peak (Fig. 6).

An estimate of $77 \AA$ for the Stokes radius of the receptor-transferrin complex was obtained from gel filtration data as described in Methods. On the basis of the assumption that the receptor-transferrin complex behaves in a fashion similar to the standard marker proteins, the molecular weight corresponding to this Stokes radius of $77 \AA$ is $\sim 310,000$. The composition of the two gel filtration peaks was further examined by SDS-PAGE and compared with that of the original microvillous membrane preparation and its detergent extracts. In the presence of $\beta$-mercaptoethanol SDSPAGE of the high molecular weight gel filtration peak (peak I) yielded nine components. The apparent molecular weights of these components were 145,000 , $120,000,89,000,77,000,65,500,61,500,57,500,45,000$, and 43,000 when compared with standard marker 


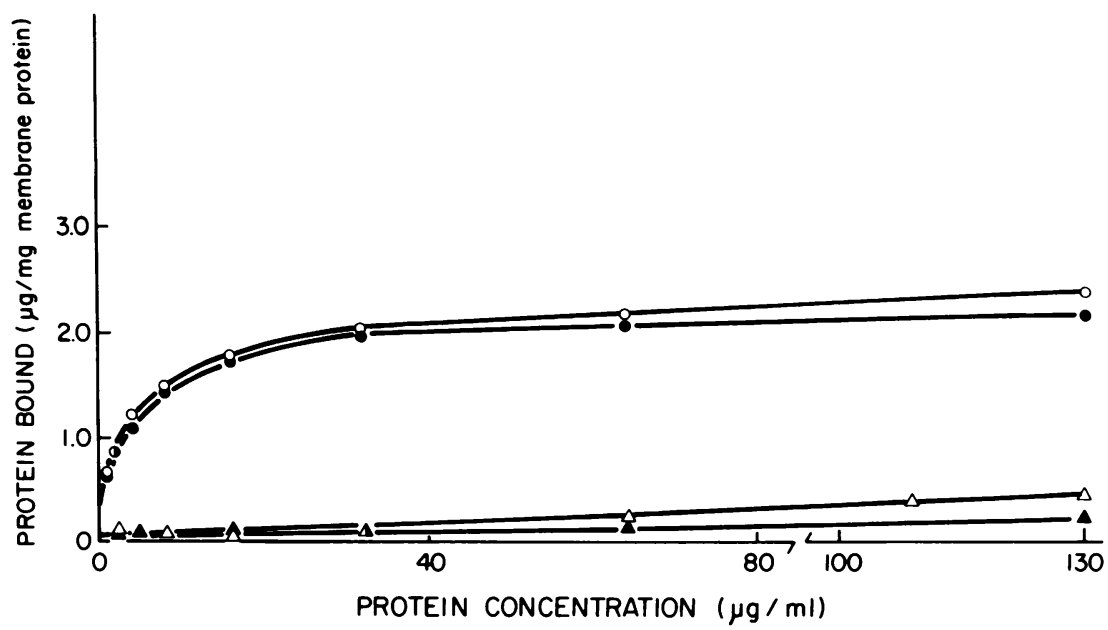

FIGURE 5 Specificity of binding. Placental microvillous membrane preparations were incubated using the standard procedure (Methods) with various concentrations of ${ }^{125}$ I-labeled transferrin in the presence $(O)$ and absence $(\Theta)$ of an equimolar concentration of ${ }^{131}$ I-labeled human albumin. The molecular weight of human transferrin was assumed to be 77,000 and that of human albumin 67,000 . Nonspecific transferrin binding to the placental microvillous membrane preparation $(\Delta)$ was determined from the uptake values of labeled transferrin in the presence of a large excess of unlabeled transferrin as described in the text. ${ }^{131} \mathrm{I}$-labeled albumin uptake $(\Delta)$ was also measured as $\mu \mathrm{g}$ albumin bound/mg microvillous membrane protein. The specific activity of ${ }^{125}$ I-labeled transferrin was $3.2 \times 10^{3} \mathrm{cpm} / \mu \mathrm{g}$ protein, and that of ${ }^{131}$ I-labeled albumin was $9.8 \times 10^{3}$ $\mathrm{cpm} / \mu \mathrm{g}$ protein.

proteins run under identical conditions. Two components, one of apparent $89,000 \mathrm{~mol}$ wt and the other of $77,000 \mathrm{~mol} w \mathrm{w}$, predominated. The latter was identified as transferrin on the basis of its ${ }^{125}$ I content and electrophoretic mobility relative to a transferrin standard run under identical conditions. Similar analysis by SDSPAGE of the lower molecular weight peak (peak II) disclosed four components. The major component was serum albumin identified by its relative electrophoretic mobility (apparent $68,000 \mathrm{~mol} \mathrm{wt}$ ) and by affinity chromatography on Blue Sepharose CL-6B (Pharmacia Fine Chemicals) (29). The other major component of peak II was transferrin. Two minor components with an apparent 60,000 and $55,000 \mathrm{~mol}$ wt were also detected.

Sucrose density gradient ultracentrifugation of receptor extracts was carried out in an attempt to achieve a higher degree of receptor purification. Teric extracts of microvillous membrane preparations that had been incubated with a saturating transferrin concentration $(40 \mu \mathrm{g} / \mathrm{ml})$ were applied to linear sucrose gradients and ultracentrifuged. The results are shown in Fig. 7. The ${ }^{125}$ I-labeled transferrin peak of greater density (14.3\% sucrose) represented the receptortransferrin complex, and the lower density peak (10.25\% sucrose) corresponded to free transferrin. These results also indicate that, unlike in gel filtration studies, most of the labeled transferrin in the extract remained associated with its receptor. Receptor material taken from the center of the high density peak was analyzed by SDS-PAGE and showed that in addition to transferrin, three components of an apparent 215,000, 180,000 , and $60,000 \mathrm{~mol}$ wt were present in the absence of $\beta$-mercaptoethanol. In the presence of $\beta$-mercaptoethanol, transferrin and two components of 90,000 and $60,000 \mathrm{~mol}$ wt were present (Fig. 7, inset). Material taken from the ultracentrifugation profile corresponding to the position of free transferrin contained in addition to transferrin a component of $60,000 \mathrm{~mol}$ wt (not shown). This method appeared to give a higher degree of receptor purification than gel filtration alone because many of the minor components previously observed were absent.

\section{DISCUSSION}

The concept of a transferrin receptor on the membranes of cells that take up transferrin and use its iron was first introduced by Jandl and co-workers $(30,31)$ in their pioneering studies on reticulocytes. Subsequent investigators have accumulated an increasing array of evidence, mainly kinetic, for the existence of transferrin receptors on reticulocytes $(26,32,33)$, marrow erythroblasts (34), placental tissues (11), Friend erythroleukemic cells (35), and lymphocytes (36). Recently, transferrin receptors have been isolated from detergent extracts of reticulocyte membranes and partially characterized $(13,23,27,28,37-44)$. The central role of 


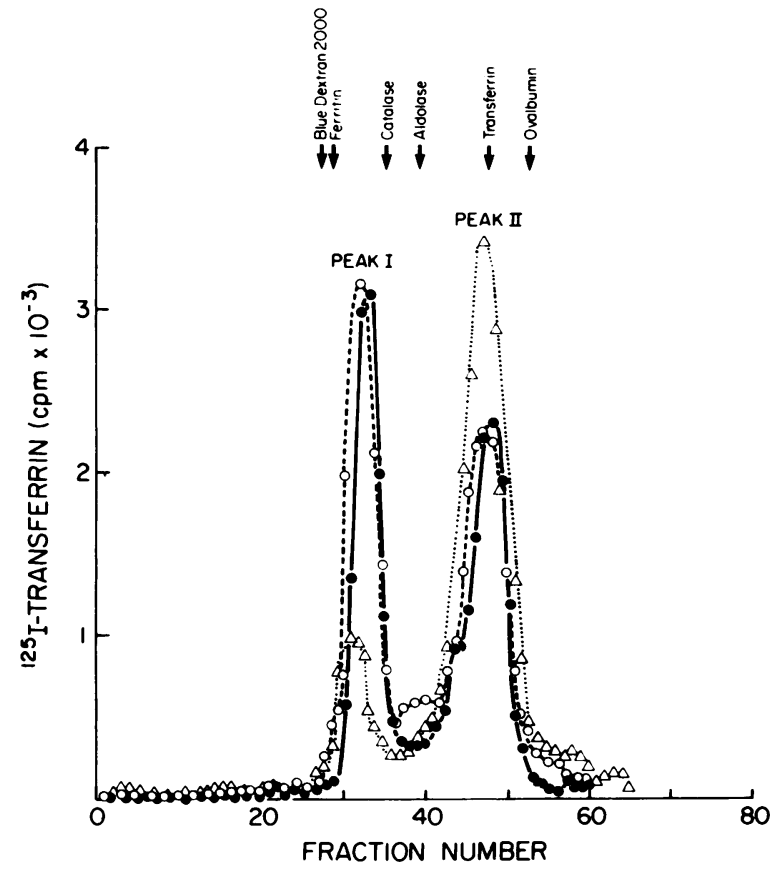

FIGURE 6 Gel filtration of an extract of microvillous membranes containing the receptor ${ }^{125}$ I-labeled transferrin complex on Ultrogel AcA34. Nonionic detergent extracts of placental microvillous membrane preparations previously incubated with $40 \mu \mathrm{g}{ }^{125} \mathrm{I}$-labeled transferrin/ml (Methods) were incubated for $20 \mathrm{~min}$ at $37^{\circ} \mathrm{C}$ in the absence (O, control) or presence of twice the concentration of unlabeled transferrin $(\Delta)$; or with $5 \mathrm{~mol}$ albumin $/ \mathrm{mol}{ }^{125}$ I-labeled transferrin present in the extract $(O)$. The figure shows the elution profiles in ${ }^{125}$ I-labeled transferrin obtained with the reaction mixtures. The column was calibrated for molecular weight and Stokes radius with standard proteins as indicated.

the reticulocyte receptor in initiating the sequence of events starting with the cellular uptake of the transferrin-iron complex and the ultimate removal of transferrin's iron by cells has been well established.

Difficulty in precisely defining the molecular weight and subunit composition of transferrin receptors in immature erythroid cells and their relationship to transferrin receptors in other cell types is apparent from the widely divergent values reported. Molecular weights of transferrin receptors from reticulocyte membranes have been variously estimated: 150,000 (38) in human; 275,000 (27), 190,000 (43), 175,000 (29), $120,000(39)$, and 36,000 (42) in rabbit; 150,000 (45) and 95,000 (44) in rat reticulocytes. Most of this variation appears to be related to difficulties in the detergent fractionation of reticulocyte membrane components, although differences in species and methods for inducing reticulocytosis may also play a role. There is less variation in recent estimates of the affinity of transferrin for reticulocyte receptors. Values of $2.3 \times 10^{7}$ $\mathbf{M}^{-1}$ for rabbit transferrin and intact rabbit reticulo- cytes (26), $4.1 \times 10^{7} \mathrm{M}^{-1}$ for solubilized rabbit reticulocyte receptors (23) have been reported.

Another readily accessible tissue for study of transferrin receptors is the placenta. In these experiments on human placenta we present evidence for the existence of a specific transferrin receptor on the microvillous membrane of syncytiotrophoblast. Transferrin uptake was rapid and saturable. Saturation of a finite number of microvillous receptors was demonstrated in experiments where specific transferrin uptake was measured under steady-state conditions over a wide (two orders of magnitude) range of transferrin concentration. At the physiologic concentration of transferrin expected in maternal plasma, the receptors were fully occupied. Transferrin binding was completely reversible. Labeled transferrin bound to microvillous membrane receptors under steady-state conditions could be rapidly and completely dissociated by competing unlabeled transferrin. Specificity for the interaction between transferrin and these receptors was indicated by the failure of albumin or gamma globulin to bind specifically to receptors or to compete with transferrin for the receptors in either intact membranes or soluble receptor preparations. The affinity of transferrin for its receptor was high $\left(K_{\mathrm{a}}\right.$ $=2.2 \times 10^{7} \mathrm{M}^{-1}$ ) and similar to affinity constants reported for reticulocytes $(23,26)$. Only one class of independent homogeneous, saturable and high affinity receptors was present. These properties established conclusively that the placental membrane vesicles contain transferrin receptors.

Attempts at further purification of the microvillous membrane transferrin receptor using nonionic detergent solubilization were carried out. Nonionic detergent solubilization preserved functional characteristics of the receptor such as specificity and reversibility of transferrin binding. Gel filtration studies indicated a Stokes radius of $\sim 77 \AA$. Although unequivocal conversion of this measurement to molecular weight cannot be made without additional information, the apparent value of $310,000 \mathrm{~mol}$ wt for the transferrinreceptor complex is in reasonable agreement with that determined from the SDS-PAGE analysis of the dense peak on sucrose density gradient centrifugation. In the absence of $\beta$-mercaptoethanol a component with 215,000-mol wt was observed, which corresponds closely to a $230,000-\mathrm{mol}$ wt calculated for the receptor when transferrin $(77,000)$ is subtracted from the 310,000 mol wt complex estimated from gel filtration data. From analysis of the components obtained from SDS-PAGE in the presence of $\beta$-mercaptoethanol, our data do not permit further precise identification of the subunit composition on the transferrin receptor. However, since submission of this manuscript, two papers have appeared and indicate that the placental receptor is a 90,000mol wt glycoprotein $(46,47)$. This value corresponds 


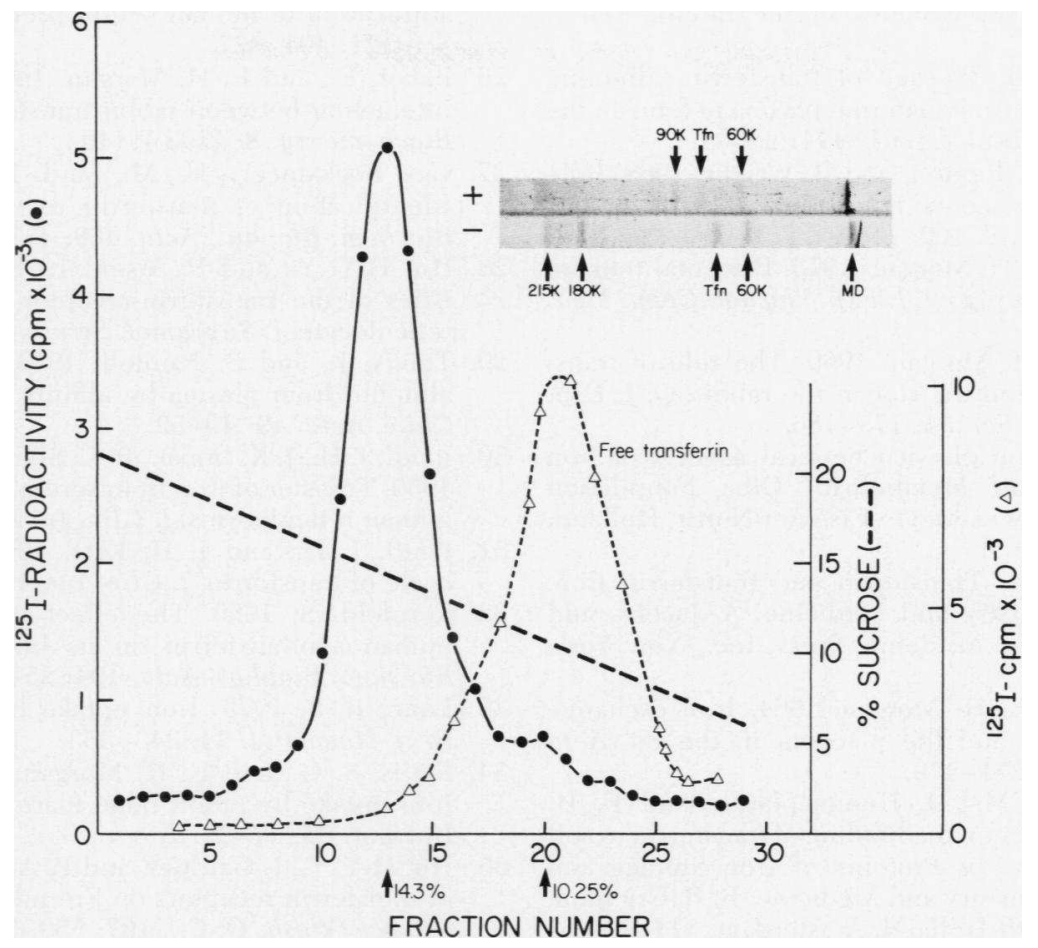

FIGURE 7 Sucrose density gradient ultracentrifugation. Ultracentrifugation profile of the placental receptor-transferrin complex $(\Theta)$ and free transferrin $(\Delta)$ on linear $7-21 \%$ (wt/vol) sucrose gradients containing 15 mosmol sodium phosphate buffer, pH 7.4, and 1\% Teric 12A9 (Methods). The inset depicts SDS-PAGE electrophoretograms of material obtained from the center of the $14.3 \%$ sucrose peak run in the presence $(+)$ and absence $(-)$ of $\beta$-mercaptoethanol with molecular weights of the components obtained by comparison with standard proteins. $\mathrm{Tfn}$, transferrin.

with a major band seen consistently in our preparations.

No evidence was found in this study for the removal of iron from transferrin bound to microvillous membrane receptors even though a recent report (48) indicates that the preparation is capable of some metabolic activity as evidenced by glucocorticoid metabolism. More rigorous studies are required to assess the possibility of such iron removal under experimental conditions in which $\mathrm{NAD}^{+}$, ATP, or other energy sources and iron chelators are included.

Finally, the availability of large amounts of functional placental transferrin receptors in this microvillous membrane preparation should allow the assessment in human placenta of the comparative binding affinity of monoferric and diferric transferrin and the examination of the Fletcher-Huehns hypothesis (49) of selective binding of one species of monoferric transferrin. The recent observation of Leibman and Aisen (50) that iron on monoferric transferrin circulating in the plasma of normal human subjects has a selective orientation on one of the two iron binding sites of transferrin raises the possibility of selective placental binding of transferrin in pregnancy (49). Since under our experi- mental conditions no metabolic conversion or scrambling of iron on transferrin seems possible with the microvillous membrane preparation, it appears ideal for the study of the biological implications of the FletcherHuehns hypothesis.

\section{ACKNOWLEDGMENT}

This work was supported in part by grant AM 16577 from the National Institutes of Health.

\section{REFERENCES}

1. Pommerenke, W. T., P. F. Hahn, W. F. Bale, and W. M. Balfour. 1942. Transmission of radioactive iron to the human fetus. Am. J. Physiol. 137: 164-170.

2. Fletcher, J., and O. E. N. Suter. 1969. The transport of iron by the human placenta. Clin. Sci. 36: 209-222.

3. Vosburgh, G. J., and L. B., Flexner. 1950. Maternal plasma as a source of iron for the fetal guinea pig. Am.J. Physiol. 161: 202-211.

4. Bothwell, T. H., W. F. Pribilla, W. Mebust, and C. A. Finch. 1958. Iron metabolism in the pregnant rabbit: iron transfer across the placenta. Am.J. Physiol. 163: 615-622.

5. Davies, J., E. B. Brown, D. Stewart, C. W. Terry, and J. Sisson. 1959. Transfer of radioactive iron via the placenta 
and accessory fetal membranes in the rabbit. Am. J. Physiol. 197: 87-92.

6. Morgan, E. H. 1964. Passage of transferrin, albumin, and gamma globulin from maternal plasma to fetus in the rat and rabbit. J. Physiol. (Lond.) 171: 26-41.

7. Douglas, T. A., J. P. Renton, and R. Wright. 1968. Role of transferrin in the placental transfer of iron in the rabbit. Am. J. Obstet. Gynecol. 102: 1169-1172.

8. Wong, C. T., and E. H. Morgan. 1973. Placental transfer of iron in the guinea pig. Q.J. Exp. Physiol. Cogn. Med. Sci. 58: $47-58$.

9. Baker, E., and E. H. Morgan. 1969. The role of transferrin in placental iron transfer in the rabbit. Q. J. Exp. Physiol. Cogn. Med. Sci. 54: 173-186.

10. Aisen, P. 1977. Some physicochemical aspects of iron metabolism. In Iron Netabolism. Ciba Foundation Symposium 51 (new series). Elsevier/North Holland, Amsterdam. 1-14.

11. Morgan, E. H. 1974. Transferrin and transferrin iron. In Iron in Biochemistry and Medicine. A. Jacobs, and M. Worwood, editors. Academic Press, Inc., New York. $29-71$.

12. Laurell, C-B., and E. H. Morgan. 1964. Iron exchange between transferrin and the placenta in the rat. Acta Physiol. Scand. 62: 271-279.

13. van Bockxmeer, F. M., D. Hemmaplardh, and E. H. Morgan. 1975. Studies on the binding of transferrin to cell membrane receptors. In Proteins of Iron Storage and Transport in Biochemistry and Medicine. R. R. Crichton, editor. Elsevier/North Holland, Amsterdam. 111-119.

14. King, B. F. 1976. Localization of transferrin on the surface of the human placenta by electron microscopic immunocytochemistry. Anat. Rec. 186: 151-160.

15. Smith, N. C., M. G. Brush, and S. Luckett. 1974. Preparation of human placental villous surface membrane. Nature (Lond.) 252: 302-303.

16. Smith, C. H., D. M. Nelson, B. F. King, T. M. Donohue, S. M. Ruzycki, and L. K. Kelley. 1977. Characterization of a microvillous membrane preparation from human placental syncytiotrophoblast: a morphologic, biochemical and physiologic study. Am. J. Obstet. Gynecol. 128: 190-196.

17. Kelley, L. K., B. F. King, L. W. Johnson, and C. H. Smith. 1979. Protein composition and structure of human placental microvillous membrane: external surface, sialic acid containing, extrinsic and intrinsic components. Exp. Cell Res. 54: 173-186.

18. Lowry, O. H., N. J. Rosebrough, L. A. Farr, and R. J. Randall. 1951. Protein measurement with the Folin phenol reagent. J. Biol. Chem. 193: 265-275.

19. Harris, D. C., and P. Aisen. 1975. Iron-donating properties of transferrin. Biochemistry. 14: 262-268.

20. McFarlane, A. S. 1963. In vivo behavior of $\mathrm{I}^{131}$-fibrinogen. J. Clin. Invest. 42: 346-361.

21. Harris, D. C., G. A. Gray, and P. Aisen. $1974 .{ }^{13} \mathrm{C}$ nuclear magnetic resonance study of the spatial relation of the metal- and anion-binding sites of human transferrin. J. Biol. Chem. 249: 5261-5264.

22. Phillips, J. L. 1976. "Specific" binding of radioiodinated transferrin to polypropylene culture tubes. Biochem. Biophys. Res. Commun. 71: 726-732.

23. van Bockxmeer, F. M., G. K. Yates, and E. M. Morgan. 1978. Interaction of transferrin with solubilized receptors from reticulocytes. Eur. J. Biochem. 92: 147-154.

24. Laemmli, U. K. 1970. Cleavage of structural proteins during the assembly of the head of bacteriophage T4. Nature (Lond.). 227: 680-685.

25. Davis, B. J. 1964. Disc electrophoresis. II. Method and application to human serum proteins. Ann. N. Y. Acad. Sci. 121: 404-427.

26. Baker, E., and E. H. Morgan. 1969. The kinetics of the interaction between rabbit transferrin and reticulocytes. Biochemistry. 8: 1133-1140.

27. van Bockxmeer, F. M., and E. H. Morgan. 1977. Identification of transferrin receptors in reticulocytes. Biochem. Biophys. Acta. 468: 437-450.

28. Hu, H-Y. Y., and P. Aisen. 1978. Molecular characteristic's of the transferrin-receptor complex of the rabbit reticulocyte. J. Supramol. Struct. 8: 349-360.

29. Travis, J., and R. Pannell. 1973. Selective removal of albumin from plasma by affinity chromatography. Clin. Chim. Acta. 49: 49-52.

30. Jandl, J. H., J. K. Inman, R. L. Simmons, and D. W. Allen. 1959. Transfer of iron from serum iron-binding protein to human reticulocytes. J. Clin. Invest. 38: 161-185.

31. Jandl, J. H., and J. H. Katz. 1963. The plasma-to-cell cycle of transferrin. J. Clin. Invest. 42: 314-326.

32. Kornfeld, S. 1969. The effect of metal attachment to human apotransferrin on its binding to reticulocytes. Biochem. Biophys. Acta. 194: 25-33.

33. Lane, R. S. 1973. Iron uptake by rabbit reticulocytes. Br. J. Haematol. 24: 343-353.

34. Kailis, S. G., and E. H. Morgan. 1974. Transferrin and iron uptake by rabbit bone marrow cells in vitro. Br. J. Haemat. 28: $37-52$.

35. Hu, H-Y. Y., J. Gardner, and P. Aisen. 1977. Inducibility of transferrin receptors on Friend erythroleukemic cells. Science (Wash. D. C.). 197: 559-561.

36. J. W. Larrick, and P. Cresswell. 1979. Transferrin receptors on human $B$ and $T$ lymphoblastoid cell lines. Biochim. Biophys. Acta. 583: 483-490.

37. Garrett, N. G., R. J. Garrett, and J. W. Archdeacon. 1973. Biochim. Biophys. Res. Commun. 52: 466-474.

38. Speyer, B. E., and J. Fielding. 1974. Chromatographic fractionation of human reticulocytes after uptake of double labeled $\left[{ }^{59} \mathrm{Fe}\right.$, $\left.{ }^{125} \mathrm{I}\right]$ transferrin. Biochim. Biophys. Acta. 332: $192-200$.

39. Sly, D. A., D. Grolich, and A. Bezkorovainy. 1975. Transferrin receptors from reticulocyte membranes and cytosol. In Proteins of Iron Storage and Transport in Biochemistry and Medicine. R. R. Crichton, editor. Elsevier/North Holland, Amsterdam. 141-144.

40. Ecarot-Charrier, B., V. Grey, A. Wilczynska, and H. M. Schulman. 1977. The isolation of transferrin receptors from reticulocyte membranes. In Proteins of Iron Metabolism. E. B. Brown, P. Aisen, J. Fielding, and R. R. Crichton, editors. Grune \& Stratton, Inc., New York. 291-298.

41. Leibman, A., and P. Aisen. 1977. Transferrin receptor of the rabbit reticulocyte. Biochemistry. 16: 1268-1272.

42. Light, N. D. 1977. The isolation and partial characterization of transferrin binding components of the rabbit reticulocyte plasma membrane. Biochim. Biophys. Acta. 495: $46-57$.

43. Witt, D. P., and R. C. Woodworth. 1978. Identification of the transferrin receptor of the rabbit reticulocyte. Biochemistry. 17: 3913-3917.

44. Sullivan, A. L., and L. R. Weintraub. 1978. Identification of ${ }^{125}$ I-labeled rat reticulocyte membrane proteins with affinity for transferrin. Blood. 52: 436-446.

45. Van Der Huel, C., M. J. Kroos, and H. G. van Eijk. 1978. Binding sites of iron transferrin on rat reticulocytes. Inhibition by specific antibodies. Biochim. Biophys. Acta. 511: 430-441. 
46. Seligman, P. A., R. B. Schleicher, and R. H. Allen. 1979. Isolation and characterization of the transferrin receptor from human placenta. J. Biol. Chem. 254: 9943-9946.

47. Wada, H. G., P. E. Hass, and H. H. Sussman. 1979. Transferrin receptor in human placental brush border membranes. J. Biol. Chem. 254: 12629-12635.

48. Fant, M. E., R. D. Harbison, and R. W. Harrison. 1979.
Glucocorticoid uptake into human placental membrane vesicles. J. Biol. Chem. 254: 6218-6221.

49. Fletcher, J., and E. R. Huehns. 1968. Function of transferrin. Nature (Lond.). 218: 1211-1214.

50. Leibman, A., and P. Aisen. 1979. Distribution of iron between the binding sites of transferrin in serum: methods and results in normal human subjects. Blood. 53: 1058-1065. 